\title{
Dificuldades no desenvolvimento de uma vacina para a esquistossomose mansoni
}

\author{
Problems in the development of a vaccine against \\ schistosomiasis mansoni
}

\begin{abstract}
Naftale Katz
Resumo Nas últimas duas décadas, os estudos com antígenos que possam conferir imunidade protetora à infecção experimental pelo Schistosoma mansoni tiveram grande impulso, especialmente devido ao avanço dos conhecimentos nos campos da biologia molecular e da imunologia. Embora, estes estudos tenham trazidos novas e importantes contribuições, até o momento, a proteção conferida tem girado em torno de $50 \%$ de diminuição do número de vermes e com alguns antígenos, também do número de ovos. As muitas perguntas ainda não respondidas indicam a necessidade de novas pesquisas a serem realizadas em animais de pequeno e grande porte, antes que estes antígenos candidatos a vacina, possam ser utlizados em ensaios clínicos.

Palavras-chaves: Vacina. Esquistossomose mansoni. Antígenos protetores. Ensaios experimentais. Ensaios clínicos.

Abstract During the last two decades, studies on antigens that may confer protective immunity to experimental infection with Schistosoma mansoni have made great advances, due largely to increased knowledge in the fields of molecular biology and immunology. Although these studies have made new and important contributions, at the present time the degree of protection conferred remains at approximately $50 \%$ in reducing the number of flukes and, with some antigens, the number of eggs. The many questions still to be answered indicate the necessity of carrying out further research on small and large animals before these antigen candidates for vaccines can be used in clinical tests.
\end{abstract}

Key-words: Vaccine. Schistosomiasis mansoni. Protection antigens. Experimental tests. Clinical tests.

Estima-se que a esquistossomose mansoni acometa mais de 70 milhões de pessoas em muitas regiões no mundo, afetando principalmente dois continentes, as Américas (Brasil, Surinam, Venezuela, Porto Rico e algumas ilhas do Caribe) e a África (quase toda sua extensão, ou seja, 53 países) e também alguns países mediterraneos ${ }^{24}$.

O controle da esquistossomose deve ser considerado sob dois aspectos, ou seja, o da morbidade e o da transmissão. Para o controle da morbidade, que visa diminuir o aparecimento de casos da forma grave (hepatoesplênica), o diagnóstico e o tratamento são suficientes.

Desde a década de 80, estão disponíveis duas drogas eficientes, com baixa toxicidade e boa tolerância, administradas em dose única por via oral.

Já para o controle da transmissão, que é o ideal a ser buscado, pois visa interromper o ciclo evolutivo do parasito, apenas o tratamento das populações infectadas não é suficiente. São necessárias obras de engenharia sanitária,

\footnotetext{
Laboratório de Esquistossomose, Centro de Pesquisas René Rachou, Belo Horizonte, MG, Brasil.

Endereço para correspondência: Dr. Naftale Katz. Centro de Pesquisas René Rachou. Av. Augusto de Lima 1715, $30100-002$ Belo Horizonte, MG, Brasil.

Fax: 5531 295-3115.

E-mail: nkatz@netra.cpqrr.fiocruz.br

Recebido para publicação em 4/5/99.
} 
possibilitando o aporte adequado de água para as casas e a adequada eliminação dos dejetos, impedindo que os mesmos contaminem os recursos hídricos, além de obras que modifiquem o meio ambiente. Outra medida importante é a educação para saúde, fazendo com que as populações residentes em zonas endêmicas não apenas tenham consciência do problema, mas que modifiquem o seu comportamento ${ }^{10}$.

O argumento economicista, para não priorizar obras de saneamento básico, é de que somos um país em desenvolvimento e sem recursos financeiros para esta empreitada. Embora, o investimento inicial para fornecer às populações água e esgoto em boas condições, seja realmente de grande monta, o resultado obtido a médio e longo prazos será muito melhor e mais barato do que a realização de diagnóstico e tratamento repetidos, pois as pessoas tratadas e curadas freqüentemente reinfectam. Considere-se ainda que as obras de engenharia sanitária previnem não apenas a esquistossomose, mas muitas outras doenças de veiculação hídrica, como, por exemplo, hepatites, gastroenterites, salmoneloses, giardoses, etc. Ao final, resultados melhores e com menos custo ${ }^{11}$.

Nos últimos anos, grandes esforços (everbas) vêm sendo despendidos pelos organismos internacionais e institutos de pesquisa visando descobrir uma vacina contra a esquistossomose, que poderia, através da imunização preventiva, impedir que as pessoas se infectassem durante o contato com águas contaminadas, durante a realização de trabalho diário, lazer, manobras militares, etc.

Embora consideremos que o caminho mais adequado seja o do saneamento básico associado ao tratamento específico para o controle da esquistossomose, fomos (e somos) obrigados a reconhecer as dificuldades política e econômica do momento, que impedem ou dificultam o uso destas medidas nos países subdesenvolvidos, e assim sendo, a vacina, quando e se existente, poderia ser também um instrumento complementar de controle.

Para o S. japonicum, a vacina seria mais importante porque permitiria o uso em animais que são importantes na cadeia de transmissão desta parasitose como búfalos na China e nas Philipinas.

Alguns autores, como Mitchell ${ }^{14}$ consideram que a vacina justifica-se especialmente para aquelas doenças cuja terapêutica é precária ou inexistente.

Características de uma vacina ideal. A vacina ideal deverá ter as seguintes qualidades (Tabela 1): ser administrada por via oral e em dose única. Isto não só facilitaria em muito a administração da mesma a grandes populações em zonas

Tabela 1 - Características de uma vacina ideal contra a esquistossomose mansoni.

\begin{aligned} & \hline Tabela 1 - Características de uma vacina ideal contra a esquistossomose mansoni. \\ & \hline \multicolumn{1}{c}{ Vacina ideal } \\ & \hline$\cdot$ Dose única \\ &$\cdot$ Administração oral \\ &$\cdot$ Custo baixo \\ &$\cdot$ Imunidade permanente (longa duração) \\ &$\cdot$ Atividade protetora em crianças pré-escolares \\ &$\cdot$ Associação com outras vacinas \\ &$\cdot$ Não produza efeitos tóxicos e/ou patológicos \\ & \hline\end{aligned}

endêmicas, como reduziria custos. Isto nos leva à terceira característica importante que é o baixo custo. De fato, Guyatt e Evans ${ }^{9}$ analisaram a relação entre custo e eficácia de uma vacina em relação especialmente à duração da proteção induzida, e ao número de doses necessárias. Concluem que para a vacina ser útil, se for de longa duração (15 anos), não poderá custar mais do que US $\$ 4.30$ por pessoa quando comparada com a quimioterapia. Se a vacina for de curta duração não poderá exceder a US\$3.50. Isto sempre considerando uma única dose.

Deve-se lembrar que o custo atual de um comprimido contendo $600 \mathrm{mg}$ de praziquantel está em torno de US\$0.12 (doze centavos de dolar) (Preço de Farmaguinhos, instituição de produção de fármacos da Fundação Oswaldo Cruz, órgão do Ministério da Saúde do Brasil).

Outra característica importante é que a vacina ofereça proteção de longa duração. Sabe-se que 
o pico da prevalência da esquistossomose em zonas endêmicas encontra-se geralmente no grupo de 10-15 anos. Portanto, se for factível que uma vacina integre o Programa Nacional de Imunizações (PNI) do país, a imunização será de execução mais fácil, e com conseqüente custo mais baixo. Outra importante característica seria a capacidade de induzir atividade protetora em crianças pré-escolares. Sabe-se que em zonas endêmicas de alta prevalência não é raro encontrar-se crianças infectadas já a partir de um ou dois anos de idade.

Obviamente, a vacina não deve produzir efeitos tóxicos e/ou patológicos e não deve exacerbar infecção pré-existente. Ressalte-se que atualmente vários antígenos estudados como possíveis vacinas, apresentam homologia com proteínas do hospedeiro humano e a possibilidade do desencadeamento de doença auto-imune não pode ser desprezada.

Razões para o uso da vacina. Bergquist e Colley ${ }^{3}$ apresentaram cinco razões (ou racionais) para o desenvolvimento da vacina contra esquistossomose (citadas abaixo, numeradas e em negrito). Estas sofreram várias críticas, especialmente de Gryssels ${ }^{3}$ e Katz ${ }^{12}$ que podem ser assim resumidas:

1) As vacinas são únicas em prover controle com custo-efetividade de muitas doenças infecciosas. Para Katz ${ }^{12}$ não é possível prever que a vacina contra esquistossomose ofereça custo-benefício semelhante ao de outras doenças infecciosas, devido à complexidade epidemiólogica, à sua forma de transmissão e à sua extensa variação biológica e imunológica no homem.

2) Alto nível de proteção é consistentemente obtido com cercárias irradiadas. É verdade que proteção alta tem sido encontrada com cercárias irradiadas ${ }^{17}$, porém dos seis antígenos recomendados pela Organização Mundial da Saúde (ver adiante), apenas o IrV-5 é baseado nos trabalhos com cercárias irradiadas. Nada garante que será possível conseguir proteção alta com os demais antígenos. Até o momento, a proteção é de apenas 40 a $70 \%$, medida com redução do número de vermes em animais de laboratório considerados bons hospedeiros, como o camundongo. Vale lembrar que Woolhouse ${ }^{23}$ utilizando-se de um modelo matemático complexo, conclui que uma vacina administrada logo após o nascimento de uma criança, que produza uma proteção inicial de 87\% por um período médio de 10 anos, levará à redução de apenas 12\% na carga de vermes acumulada.

3) A reinfecção rápida após o tratamento torna a quimioterapia dispendiosa. É interessante notar que os autores não quantificam o que é rápido, mas mesmo que estejam referindo-se a um ou dois anos, o custo-benefício obtido reduz a importância do argumento, quando o objetivo é o controle da morbidade. Como parece estar muito bem demonstrado, no Brasil, um único tratamento é suficiente para prevenir o aparecimento da forma hépato-esplênica da esquistossomose, seja até seis anos após o tratamento, em Caatinga do Moura, Bahia ${ }^{4}$ ou em áreas endêmicas de Minas Gerais, como Peri-Peri e Comercinho com períodos de observação de respectivamente 14 anos ou até quase 20 anos (Katz e Rocha, 1999, dados não publicados). Um único tratamento parece ser uma vacina anti-forma grave (hepatoesplênica) ideal, que dificilmente será superada por qualquer outra.

4) A distribuição do medicamento requer uma infra-estrutura substancial para cobrir todas as áreas endêmicas regularmente. Esta crítica à quimioterapia aplica-se também para a distribuição da vacina, se o objetivo é alcançar massas populacionais residentes em zonas endêmicas.

Acrescente-se ainda, que se o objetivo é o controle da morbidade, a quimioterapia poderá ser usada a cada três anos ou mais dependendo da força de transmissão da área. Além disso, se as medidas de controle da esquistossomose estiverem devidamente repassadas ao Serviço de Saúde local, os pacientes porventura reinfectados passam a ser tratados de forma rotineira, dispensando a necessidade de programas especiais e reduzindo ainda mais os custos.

5) A expansão de programas de quimioterapia trazem consigo o espectro da resistência à drogas. Esta é uma possibilidade teórica que não pode ser desprezada. Todavia, até o momento, não existe nenhuma área endêmica, das muitas onde o tratamento foi repetidamente utilizado, onde tenha surgido resistência às drogas esquistossomicidas, embora casos de pacientes repetidamente tratados e não curados tenham sido relatados, incluindo casos em que as cepas isoladas mostraram resistência (ou baixa susceptibilidade) às drogas em animais de laboratório ${ }^{7}$.

Para Gryssels ${ }^{3}$, o reduzido nível de morbidade, especialmente após os programas de quimioterapia, 
pode não justificar o desenvolvimento e aplicação de uma vacina e além disto, a avaliação da atividade da vacina será muito difícil.

A propósito desta última assertiva, Basch ${ }^{2}$ enumera pesquisas adicionais e desenvolvimento necessários antes que uma vacina possa ser avaliada quanto à sua eficiência e que resumidamente seriam: métodos de detecção de penetração de cercária e da infecção inicial; detecção de esquistossômulos, vermes, imaturos e infecção unisexual; diferenciação entre a imunidade natural e a induzida por vacina no hospedeiro humano; caracterização do estágio da doença esquistossomótica por critérios bem definidos; seguimento da infecção e determinação do tipo e extensão da patologia por meios nãoinvasivos; métodos de avaliação da carga parasitária; verificação da presença de vermes vivos através do achado de antígenos ou seus metabólitos no sangue, saliva, fezes ou urina; adaptação destes métodos para uso no campo; definir e medir proteção; caracterizar e medir os efeitos adversos da vacina.

Considerações éticas. As condições éticas para um ensaio no campo da vacina devem ser colocados em primeiro plano.

Além de seguir os princípios já determinados para estudos desta natureza, ou seja ser aprovado previamente por uma Comissão de Ética local e nacional, ter o consentimento por escrito de cada pessoa envolvida (neste caso agravado pelo fato de serem crianças pré-escolares e portanto será obrigatório o consentimento dos pais após explicação do ensaio), algumas questões específicas devem ser consideradas.

Os testes de vacinação só podem ser feitos em áreas com transmissão sendo assim, logo que os indivíduos apresentarem-se infectados deverão ser tratados especificamente. Não é admissível que os indivíduos infectados sejam mantidos sem tratamento após diagnóstico.

Esta afirmativa leva a um problema maior que se refere a como fazer avaliação de uma vacina que protegeria o aparecimento de formas graves. De fato, é comum encontrar-se como argumento que a vacina para esquistossomose não necessitaria produzir proteção total, mas apenas diminuição da carga parasitária (medida pelo número de ovos de $S$. mansoni nas fezes). Embora não esteja demonstrando que esta diminuição impediria o aparecimento das formas hépato-esplênicas, eticamente não podemos e não devemos deixar estes indivíduos sem tratamento para ver se irão ou não desenvolver formas graves. Portanto, existe uma impossibilidade ética de se fazer avaliação da vacina visando a prevenção das formas graves, uma vez que a população vacinada teria que ser seguida por alguns anos sem tratamento. Como já referido anteriormente, o tratamento quimioterápico por si só já evita o aparecimento destas formas.

A utilização da vacina parece muito mais indicada para visitantes provenientes de zonas não endêmicas sejam nacionais ou estrangeiros. Sendo assim, após a utilização da comunidade para o ensaio inicial, quem continuará garantindo novas vacinações a esta comunidade? Caso isto não ocorra, a comunidade estará apenas sendo explorada e servindo como cobaia.

Acrescente-se, que não houve ainda nenhum fórum de discussão sobre implicações e normatizações éticas envolvendo a vacina contra a esquistossomose, a exemplo de vacinas desenvolvidas contra outras infecções, incluindo debates amplos com a sociedade civil e grupos representativos das populações interessadas.

Vacinas candidatas. São seis os antígenos considerados pela Organização Mundial de Saúde como os mais promissores quando a meta é obtenção da vacina contra a esquistossomose (Tabela 2).

Como pode ser visto, na Tabela 2, a proteção medida pela diminuição do número de vermes encontrados no sistema porta, varia entre os diferentes antígenos mas, nunca ultrapassando $70 \%$. Na realidade, diferentes experiências feitas pelos mesmos autores com partidas diferentes de antígenos tem apresentado variações entre 40 a $70 \%$, quando se considera os resultados obtidos em camundongos. Deve-se destacar ainda, que cepas diferentes de camundongos apresentam respostas diferentes de proteção para o mesmo antígeno ${ }^{19}$.

Em 1995, a OMS coordenou ensaios experimentais com estes seis antígenos, para verificar a atividade dos mesmos por laboratórios independentes. Dois laboratórios experientes, um nos EUA e outro na Inglaterra, usando duas cepas de camundongos C57BL6 e BALB/C testaram os 6 antígenos, de acordo com os esquemas indicados pelos autores. Com nenhum destes antígenos testados houve redução maior que $40 \%$ do número de vermes. As hipóteses aventadas para este resultado negativo foram: problema com a estabilidade dos antígenos, falta de padronização dos ensaios e de adjuvante 
Tabela 2 - Antígens candidatos a vacina contra esquistossomose, selecionado.

\begin{tabular}{|c|c|c|c|c|c|}
\hline Antígeno & Função & $\begin{array}{c}\text { Proteção } \\
\text { (animais isogênicos) }\end{array}$ & $\begin{array}{c}\text { Lugar de } \\
\text { desenvolvimento }\end{array}$ & Estado legal & Refs \\
\hline $\begin{array}{l}\text { Glutathione S-transferas } \\
\text { (P28/GST) }\end{array}$ & Enzima & $30-60$ & Institut Pasteur, Lille, France & Patenteado & 6 \\
\hline Paramyosin (Sm97) & Proteína muscular & 30 & $\begin{array}{c}\text { Case Western Reserve University/ } \\
\text { National Institutes of Health/ } \\
\text { Cornell University, USA }\end{array}$ & Domínio público & 15 \\
\hline IrV-5 (62 kd) & Proteína muscular & $50-70$ & $\begin{array}{c}\text { Johns Hopkins School } \\
\text { of Medicine, Baltimore, USA }\end{array}$ & Patenteado & 21 \\
\hline $\begin{array}{l}\text { Triose phosphate } \\
\text { isomerase (TPI) } \\
(28 \mathrm{kd})\end{array}$ & Antígeno de membrana & $30-60$ & $\begin{array}{c}\text { Harvard School of Public } \\
\text { Health, Boston, USA }\end{array}$ & Domínio público & 16 \\
\hline Sm 23 & Antígeno de membrana & $40-50$ & $\begin{array}{l}\text { Johns Hopkins School of Medicine/ } \\
\text { Harvard School of Public Health, USA }\end{array}$ & Domínio público & 18 \\
\hline Sm14 & Antígeno de membrana & $40-65^{a}$ & $\begin{array}{l}\text { Fundação Oswaldo Cruz } \\
\text { Rio de Janeiro, Brasil }\end{array}$ & Patenteado & 22 \\
\hline
\end{tabular}

a - animais singênicos

Fonte: Bergquist e Colley, 1998 com pequenas modificações.

efetivo. Ao invés de repetir os ensaios experimentais, a UPDP/World Bank/WHO Special Programme for Research and Training in Tropical Diseases sugeriu aguardar os estudos que estavam sendo realizados com soro e células de pacientes infectados com esquistossomose no Brasil, Egito e Kênia ${ }^{3}$.

Estes estudos foram desenhados para examinar a relação entre o número de ovos de S. mansoni excretados nas fezes pré e pós tratamento com a resposta celular e humoral dos pacientes aos seis antígenos. Grupos bem caracterizados de aproximadamente 200 indivíduos foram selecionados, testados e tratados, e seguidos após 3 meses e 1 ano. A contagem de ovos foi obtida bem como os níveis de isotipos de anticorpos específicos, interferon gama e interleucinas IL-2, IL-4, IL-5 e IL-10 obtidos in vitro após estimulação com os antígenos que estavam sendo estudados. Embora os dados ainda não tenham sido publicados, na íntegra, o resumo feito por Bergquist e Colley ${ }^{3}$ indica que no Egito foi possível separar populações supostamente resistentes ou susceptíveis. No Brasil, os ensaios estiveram a cargo de Amélia Ribeiro de Jesus e Edgar Marcelino de Carvalho na Bahia que mostraram uma resposta significativa na produção da IL-5 e INF- $\gamma$. Houve indicação que algumas citocinas eram especialmente induzidas por alguns antígenos. Por exemplo, a resposta da IL-5 à paramiosina e a do INF- $\gamma$ ao IrV-5y e à Sm14. No Egito, foram também observados vários graus de restrição genética aos diferentes antígenos utilizados. No Kênia, devido a um período de seca os resultados de evolução pós tratamento ficaram prejudicados.

Baseado nestes dados, que infelizmente também são apenas indicativos, numa reunião realizada no Cairo, em maio de 1997, houve recomendações para que alguns destes antígenos fossem encaminhados para a fase I de ensaios clínicos.

É interessante salientar que os antígenos americanos e alguns egípcios terão financiamento para estes ensaios vindo da USAID e Ministério da Saúde do Egito. O GST vem desde o início sendo financiado diretamente pelo Instituto Pasteur em Lille, posteriormente e temporariamente pela BDMérrieux e os ensaios clínicos estavam já programados. Os estudos com o Sm14 foram todos desenvolvidos no Brasil, com financiamento principal da Fundação Oswaldo Cruz e das agências financiadoras brasileiras, CNPq principalmente e mais recentemente, FAPEMIG.

Em janeiro de 1999, em um documento do TDR produzido pelo Steering Committee on Vaccine Discovery Research (VDR) lê-se que a expectativa com o uso da vacina para a esquistossomose é o de reduzir a reinfecção após tratamento medicamentoso em pelo menos $50 \%$ (Tabela 3 ). $\mathrm{O}$ mais curioso vem a seguir: resistência à reinfecção é considerada quando o indivíduo adquire a infecção e apresenta menos do que 50 ovos de $S$. japonicum por grama de fezes ou 
Tabela 3 - Plano de trabalho do grupo de "Vaccine Discovery Research (VDR) do TDR/UNDP/World Bank/WHO.

Expected outcomes

for schistosomiasis, to reduce reinfection following drug treatement by at least $50 \%$.

target product profile: a vaccine which induces at least $50 \%$ resistance to re-infection after drug treatment of susceptible population, as measured by egg counts (e.g. less than 50 egg per gram for $S$. japonicum or less than 100 eggs per gram for $S$. mansoni) with a duration of immunity of 3-5 years or more.

Fonte: WHO, $1999^{25}$.

menos do que 100 ovos de $S$. mansoni por grama de fezes ${ }^{25}$.

Trata-se de subversão de vários conceitos, sejam relacionados à imunização, seja à reinfecção. Além do mais, sabe-se que após o tratamento, a taxa de reinfecção varia de área para área e depende das condições ambientais e epidemiológicas das áreas endêmicas, sendo que, em duas áreas endêmicas de Minas Gerais foi verificado que nos pacientes tratados, curados e reinfectados, após dois anos, o número de ovos nas fezes é em $75 \%$ dos casos igual ou menor do que aquele encontrado antes do tratamento ${ }^{13}$.

É interessante notar, que o objetivo proposto neste documento da OMS parece que se adequa, muito mais às propriedades dos antígenos existentes e indicados como candidatos prováveis a tornarem-se vacinas, do que a buscar e encontrar uma vacina com propriedades necessárias para conferir imunidade protetora às populações residentes em zonas endêmicas.
Pelo menos dois dos antígenos citados possuem atividades em animais de grande porte, como $\mathrm{GST}^{5}$ ou apresentam atividades em outras parasitoses que acometem estes animais, como Sm14 e Fh15 para a Fasciola hepatica ${ }^{20} 22$.

A possibilidade da realização de ensaios veterinários antes de serem feitos ensaios no homem, oferece um caminho particularmente relevante no desenvolvimento de antígenos candidatos à vacinas humanas. De fato, observações em grande número de diferentes hospedeiros animais, seja quanto a proteção, seja quanto a possíveis efeitos danosos das vacinas potenciais, devem ser pré-requisitos para os ensaios clínicos.

Concluindo, a grande quantidade de perguntas ainda sem respostas e de dúvidas está claramente a indicar a necessidade de muita pesquisa, antes que os ensaios clínicos com estes antígenos candidatos à vacina possam ser iniciados de forma científica e eticamente adequada e segura.

\section{REFERÊNCIAS BIBLIOGRÁFICAS}

1. Araújo N, Katz N, Dias EP, Souza CP. Susceptibility to chemotherapeutic agents of strains of Schistosoma mansoni isolated from treated and untreated patients. American Journal of Tropical Medicine and Hygiene 29:890-894, 1980.

2. Basch PF. Antischistosomal vaccines: beyond the laboratory. Transactions of the Royal Society Tropical Medicine and Hygiene 87:589-592, 1993.

3. Bergquist NR, Colley, DG. Schistosomiasis vaccines: Research to development. Parasitology Today 14:99-104, 1998.

4. Bina JC. Influência da terapêutica específica na evolução da esquistossomose mansoni. Tese de Mestrado, Universidade Federal da Bahia, Salvador, 1977.

5. Boulanger D, Trottein F, Mauny F, Bremond P, Couret D, Pierce RJ, Kadri S, Godin C, Sellin E, Lecocq JP, Sellin, B, CapronA. Vaccination of goats against the trematode Schistosoma bovis with a recombinante homologous schistosome-derived glutathione S-transferase. Parasite Imunology 16: 339-406, 1994.

6. Boulanger D, Warter A, Trottein F, Mauny F, Brémond P, Audibert F, Couret D, Kadri S, Godin C, Sellin E, Pierce
RJ, Lecocq JP, Sellin B, Capron A. Vaccination of patas mokeys experimentally infected with Schistosoma haematobium using a recombinant gluthathione S-transferase cloned from S. mansoni. Parasite Immunology 17:361-369, 1995.

7. Dias LCS, Pedro RJ, Rigo E, Goto MF, Mafra GL. Linhagem humana de Schistosoma mansoni resistente a esquistossomicidas. Revista de Saúde Pública de São Paulo 12:110, 1978.

8. Gryssels B. In: Bergquist NR, Colley DG (eds) Schistosomiasis Vaccines: Research to Development. Parasitology Today 14:99-104, 1998.

9. Guyatt HL, Evans D. Desirable characteristics of a schistosomiasis vaccine: some implications of a costeffectiveness analysis. Acta Tropica 59:197-209, 1995.

10. Katz N. Experiências com quimioterapia em grande escala no controle da esquistossomose no Brasil. Revista do Instituto de Medicina Tropical de São Paulo 22:4051, 1980 .

11. Katz N. Vacina polivalente anti-helmintos? Biotecnologia Ciência \& Desenvolvimento Ano 1:34-35, 1997. 
12. Katz N. Schistosomiasis vaccines: The need for more research before clinical trials. Parasitology Today 15:165166, 1999

13. Katz N, Zicker, F, Rocha RS, Oliveira VB. Re-Infection of patients in schistosomiasis mansoni endemic areas after specific treatment. Revista do Instituto de Medicina Tropical de São Paulo 20:273-278, 1978.

14. Mitchell GF. Opportunitites and constraints in schistosomiasis vaccine development: Infection characteristics and industry realities. Memórias do Instituto Oswaldo Cruz 90:218-220, 1995.

15. Pearce EJ, James SL,Hienny S, Lanar D.E., Sher A. Induction of potective immunity against Schistosoma mansoni by vaccination with schistosome paramyosin (Sm97), a nonsurface parasite antigen. Proceedings of the National Academy of Sciences of the USA 85:56785682, 1988.

16. Reynolds SR, Dahl CE, Harn DA. T and B epitope determination and analysis of multiple antigenic peptides for the $S$. mansoni experimental vaccine triose-phosphate isomerase. Journal of Immunology 152:193-200, 1994.

17. Reynolds SR, Harn DA. Comparison of irradiated-cercaria schistosome vaccine models that use 15- and 50-Kilorad doses: the 15-Kilorad dose gives greater protection, smaller liver sizes, and higher gamma interferon levels after challenge. Infection and Immunity 60:90-94, 1992.

18. Reynolds SR, Shoemaker CB, Harn DA. T and B cell epitope mapping of $\mathrm{Sm23}$, an integral membrane protein S. mansoni. Journal of Immunology, 149:39954001, 1992.
19. Richter D, Harn DA. Candidate vaccine antigens identified by antibodies from mice vaccinated with 15 or - 50-Kilorad-iradiated cercariae of Schistosoma mansoni. Infection and Immunity 61:146-154, 1993.

20. Rodriguez-Pérez J, Rodríguez-Medina JR, GarciaBlanco MA, Hillyer GV. Fasciola hepatica: molecular cloning, nucleotide sequence, and expression of a gene encoding a polypeptide homologous to a Schistosoma mansoni fatty acid-binding protein. Experimental Parasitology 74:400-407, 1992.

21. Soisson LMA, Masterson CP, Tom TD, Mcnally MT, Lowell $\mathrm{GH}$. Strand M. Induction of protective immunity in mice using a 62-kDa recombinant fragment of a Schistosoma mansoni surface antigen. Journal of Immunology 149:3612-3620, 1992.

22. Tendler M, Brito CA, Vilar MM, Serra-FreireN, Diogo CM, Almeida MS, Delbem ACB, Silva JF, Savino W, Garratt RC, Katz N, Simpson AJG. A Schistosoma mansonifatty acid-binding protein, Sm14, is the potential basis of a dual-purpose anti-helminth vaccine. Proceedings of the National Academy of Sciences of the USA 93:269-273, 1996.

23. Woolhouse MEJ. Human schistosomiasis: potential consequences of vaccination. Vaccine 13:1045-1050, 1995.

24. World Health Organization. WHO Fact Sheet on Schistosomiasis. May, 1996.

25. World Health Organization. Workplan of the Steering Committee on Vaccine Discovery Research (VDR). UNDP/World Bank/WHO - TDR, 1999. 